\title{
Policing the promotion of prescription medicines - the new Medicines Australia Code of Conduct
}

\section{Barbara Mintzes \\ Associate professor, School of Pharmacy, Faculty of Medicine and Health, University of Sydney}

\section{Keywords}

advertising, conflict of interest, drug industry, Medicines Australia

Aust Prescr 2021;44:4-5 https://doi.org/10.18773/ austprescr.2020.082
In 2020, Medicines Australia, the industry organisation for research-based pharmaceutical companies, launched its latest Code of Conduct for ethical marketing. This 19th edition covers the promotion of prescription medicines and public reporting of industry payments to health professionals and health consumer groups.'

The first overarching principle in the 19th edition is that 'all activities undertaken by companies have the purpose of supporting the quality use of medicines'. Although this is an important aspirational goal, the evidence to date on the effects of promotion points to higher prescribing rates, increased costs and less appropriate prescribing. ${ }^{2}$

Regulation of pharmaceutical promotion matters to public health because inappropriate use of drugs can lead to serious harm. Intensive opioid marketing helped fuel the epidemic of opioid mortality in North America. In the USA, doctors with funding from opioid producers prescribed more opioids, and opioid-related mortality was higher in counties where more money was spent on marketing. ${ }^{3}$ Promotion can also affect health systems by fuelling higher costs, for example by encouraging more prescribing of brand-name products.

The new edition of the Medicines Australia Code of Conduct is shorter and is described as more principle-based and less prescriptive than previous codes. Users are referred to the guidelines of the 18th edition as a benchmark, suggesting the two editions have broadly similar criteria. One striking difference is that this is the first Code since the 1970s not to be authorised by the Australian Competition and Consumer Commission (ACCC). Previously, Medicines Australia had sought ACCC oversight to ensure the Code was consistent with competition law.

The ACCC played an important role in strengthening the Code in 2015, when Medicines Australia began the public reporting of payments to individual health professionals. The ACCC rejected an opt-out clause allowing clinicians to refuse consent. It also urged Medicines Australia to set up a centralised searchable database of clinician reports instead of them being scattered in many separate company documents. The name of the health professional can be entered into a search which will reveal any payments they have received.
Promotion is ubiquitous in clinical practice. Industry funds most medical research and much continuing medical education. Many clinical experts are paid by the industry to be 'key opinion leaders'. In Australia an average of 608 industry-sponsored events for clinicians are held each week, with food and drink provided at over $90 \%{ }^{4}$

In recent years more information about drug promotion has come to light because of public reports of industry payments to clinicians, especially through the US Open Payments database. There has also been the public release of internal company documents in whistle-blower legal cases concerning fraudulent marketing. ${ }^{5}$ The issues addressed in these legal cases have implications that are relevant to the quality use of medicines in Australia. These include off-label prescribing of antipsychotic drugs and overuse of gabapentinoids and opioids. Financing of clinician key opinion leaders, sponsored continuing medical education and ghost-writing have been identified as key marketing tools. ${ }^{5}$ There are many examples of ghostwriting in the medical literature. For example, dozens of reviews and commentaries promoted unproven benefits and downplayed the harms of menopausal hormone replacement therapy. ${ }^{6}$ The new Medicines Australia Code does not mention ghost-writing. There are no new restrictions on allowable payments to clinicians and no firewalls to prevent company input into the content of continuing medical education or the choice of speakers.

Research linking the US Open Payments database with prescribing data has revealed the effects of industry payments on prescribing. One important finding is that even small gifts of food and drink affect prescribing. In an analysis in four drug classes, doctors who received one industry-funded meal, costing on average less than US $\$ 20$ (A $\$ 28$ ), wrote more prescriptions for the promoted drugs. More meals were associated with more prescribing. ${ }^{7}$ In Australia, the Medicines Australia Code allows payments for meals up to $A \$ 120$, but companies are not required to report publicly on food and drink payments. Free samples and payments for research contracts are also not disclosed.

Australia was at the forefront of transparency reporting in 2007, when public reporting of industry-sponsored events was introduced. Reporting of payments to individual clinicians, introduced in 2015, was an 
important advance. Transparency about industry payments to clinicians allows the public to know the nature and extent of financial links and could lead some clinicians to avoid questionable payments. However, individual reporting was accompanied by a step backwards in terms of the types of funding disclosed, with costs of food and drink left out. As a result, the total amounts of funding disclosed dropped by onethird. ${ }^{8}$ The only hospitality that must be reported under the current Code is airfares and accommodation. Current reporting is less comprehensive than in several European countries where the transparency of industry payments is mandated by law. ${ }^{9}$ Additionally, companies that are not members of Medicines Australia may not adhere to the principles of the Code.

What about advertising standards? The Code specifies that information should be accurate, balanced and '...not mislead directly, by implication or by omission'. However, an Australian analysis of advertising claims in 290 pharmacy journal advertisements found only nine (1.5\%) of the 598 included claims were unambiguous clinical claims supported by strong published research evidence..$^{10} \mathrm{~A}$ comparison of Australian, Canadian and US advertisements in general practice journals gave Australian advertisements the lowest quality score, mainly due to limited information about harm or quantified benefits." The new Code mainly differs from previous standards in no longer specifying required minimum font sizes. It does not require quantified clinical evidence or a balance of benefits and harms in advertising copy, nor does it prohibit ambiguous or non-clinical claims. It is therefore unlikely to address the key quality concerns raised in these analyses.
Medicines Australia receives few complaints about breaches of the Code. Most complaints come from competing companies. Within a complaints-based system, why most clinicians do not submit complaints is an open question. It could be due to a lack of observed breaches, lack of awareness, lack of time, or differing priorities. Medicines Australia's Code Monitoring Committee also reviews compliance of company policies and promotional materials submitted on request. The Committee is limited to three reviews per company per year. Overall, monitoring is limited in scope and cannot assess more generally whether misleading or inaccurate information is reaching clinicians.

If the regulation of promotion is to encourage the quality use of medicines, influential payments to clinicians and commercial biases in research and education must all be addressed. This would require visionary change. The new Medicines Australia Code of Conduct largely retains existing standards despite the international research evidence showing the adverse effects of promotion, such as the concerning experience with opioids. Gaps in transparency reporting persist, especially compared with national legislated public reporting systems overseas. From a public health perspective, more robust regulation is needed. $<$

Conflict of interest: In 2020, Barbara Mintzes acted as an expert witness for Health Canada in a legal case on marketing of an unapproved product. She is also a member of Health Action International (HAl-Europe), a non-profit organisation supporting rational medicine use and access to essential medicines.

\section{REFERENCES}

1. Medicines Australia. Code of Conduct. 19th ed. Adopted 26 Nov 2019. Effective 30 Mar 2020

https://www.medicinesaustralia.com.au/code-of-conduct/ code-of-conduct-current-edition [cited 2021 Jan 4]

2. Spurling GK, Mansfield PR, Montgomery BD, Lexchin J, Doust J, Othman N, et al. Information from pharmaceutical companies and the quality, quantity, and cost of physicians prescribing: a systematic review. PLoS Med 2010;7:e1000352. https://doi.org/10.1371/journal.pmed.1000352

3. Hadland SE, Rivera-Aguirre A, Marshall BD, Cerdá M. Association of pharmaceutical industry marketing of opioid products with mortality from opioid-related overdoses. JAMA Netw Open 2019;2:e186007. https://doi.org/10.1001/ jamanetworkopen.2018.6007

4. Fabbri A, Grundy Q, Mintzes B, Swandari S, Moynihan R, Walkom E, et al. A cross-sectional analysis of pharmaceutical industry-funded events for health professionals in Australia. BMJ Open 2017;7:e016701. https://doi.org/10.1136/ bmjopen-2017-016701

5. Kesselheim AS, Mello MM, Studdert DM. Strategies and practices in off-label marketing of pharmaceuticals: a retrospective analysis of whistleblower complaints. PLoS Med 2011;8:e1000431. https://doi.org/10.1371/journal.pmed.1000431

6. Fugh-Berman AJ. The haunting of medical journals: how ghostwriting sold "HRT". PLoS Med 2010;7:e1000335. https://doi.org/10.1371/journal.pmed.1000335
7. DeJong C, Aguilar T, Tseng CW, Lin GA, Boscardin WJ Dudley RA. Pharmaceutical industry-sponsored meals and physician prescribing patterns for medicare beneficiaries. JAMA Intern Med 2016;176:1114-22. https://doi.org/10.1001/ jamainternmed.2016.2765

8. Parker L, Karanges EA, Bero L. Changes in the type and amount of spending disclosed by Australian pharmaceutical companies: an observational study. BMJ Open 2019;9:e024928. https://doi.org/10.1136/ bmjopen-2018-024928

9. Fabbri A, Santos A, Mezinska S, Mulinari S, Mintzes B. Sunshine policies and murky shadows in Europe: disclosure of pharmaceutical industry payments to health professionals in nine European countries. Int J Health Policy Manag 2018;7:504-9. https://doi.org/10.15171/ijhpm.2018.20

10. Mandoh M, Curtain CM. Quality of claims and references found in Australian pharmacy journal advertisements. Int J Pharm Pract 2017;25:365-70. https://doi.org/10.1111/ ijpp.12326

11. Diep D, Mosleh-Shirazi A, Lexchin J. Quality of advertisements for prescription drugs in family practice medical journals published in Australia, Canada and the USA with different regulatory controls: a cross-sectional study. BMJ Open 2020;10:e034993. https://doi.org/10.1136/ bmjopen-2019-034993 